\title{
COMMUNITY-ORIENTATED MEDICAL PRACTICE FOR THE UNIVERSITY OF LIVERPOOL MEDICAL STUDENTS IN MORECAMBE BAY: THE STORY SO FAR
}

\author{
J Gardner, Primary Care Coordinator \\ Morecambe Bay Primary Care Trust
}

\begin{abstract}
Following Mike Flanagan's article in the September 2001 issue of the journal, which concentrated on hospital-based activities, this article describes the primary care initiatives underway in respect of Liverpool University Medical School. The article covers the background and build-up to the present situation and outlines anticipated developments.
\end{abstract}

\section{INTRODUCTION}

On June 22nd 1999, the then health minister, John Denham, announced that Liverpool University Medical School's annual intake would expand by 50 students from October 2001. Explicit in Liverpool's bid for expansion was the proposal that these new students would spend Years 4 and 5 of their medical school experience in Morecambe Bay. Amongst others, Morecambe Bay Health Authority (MBHA), Morecambe Bay Hospitals Trust and Lancaster University supported Liverpool's bid. Of course, Morecambe Bay already had a close liaison with Manchester University Medical School across both primary and secondary care, so one might ask why Manchester's parallel expansion did not focus on this area rather than Liverpool. The reality is that the two medical schools looked to rationalise their respective geographical exposure and Manchester focussed on increased links with Keele University and Staffordshire whilst Liverpool looked to Morecambe Bay and North Wales.

Morecambe Bay Health Authority and Morecambe Bay Primary Care Trust recognised the strategic importance of encouraging the expansion of undergraduate medical student training in the area. They argued that increased numbers of students coming to the area could improve clinical practice, enhance job satisfaction, promote inward investment and facilitate the recruitment and retention of the medical workforce. In addition, they believed that Morecambe Bay has much to offer medical students in terms of a wellrounded, rewarding and enjoyable educational experience with a style of its own.

Although the development plans are for the bulk of new students to begin training in Morecambe Bay in September 2004, important initiatives began in September 2000. The steering committee, set up in late 1999 to oversee developments, soon recognised that the primary care community across Morecambe Bay already had the capacity to begin taking students in a co-ordinated fashion and in significant numbers. An understanding of this capacity came from a questionnaire survey of the 59 practices across
Morecambe Bay undertaken in September 1999. The questionnaire asked about current training activity, ambitions for future training activity, available practice facilities and possible capital requirements to support future training activity.

\section{QUESTIONNAIRE RESULTS}

\author{
Responses \\ 45 practice responses in total (from a possible 59) \\ 13 from Barrow LHG area \\ 15 from Lancaster LHG area \\ 21 from South Lakes LHG area
}

\section{Practices involved in medical student training in 1999}

22 of the 45 responding practices reported current medical student training involvement, some taking students from more than one medical school.

15 practices indicated involvement with Manchester Medical School

9 practices indicated involvement with Newcastle Medical School

1 practice indicated involvement with Imperial College, London

1 practice indicated involvement with University College Hospital, London

Practice involvement by LHG area

Barrow \& Ulverston 9 Plus Millom Practice $=10$

Lancaster

South Lakes

6

Practice interest in future medical student teaching Yes 41

No 4 All cited lack of time as the reason for saying 'no'

Practice interest in future development workshops for the primary care teams

Yes 40

No 5 Some cited previous experience as reason for saying 'no'

Key topics to be covered

(From a picking list): The Liverpool curriculum problem based learning teaching skills 


\section{PRACTICE FACILITIES ALREADY IN PLACE FOR TEACHING}

The basic minimum requirement for teaching was described as the availability of a clinical room (for sole use by a student at certain times), on-site library/internet facilities, and a rest/quiet room.

$\begin{array}{lr}\text { clinical room } & 34 \\ \text { rest/quiet room } & 32 \\ \text { library/internet } & 34 \\ \text { none of these } & 3 \\ \text { all three ready } & 29\end{array}$

On the basis of this questionnaire and qualitative evidence from across the Morecambe Bay primary care community, it was evident that capacity and enthusiasm existed already in 2000 to extend medical student training. There was no intention or desire to restrict students from other medical schools coming to Morecambe Bay, but the clear MBHA strategy was now to promote Liverpool Medical School

\section{GETTING THINGS STARTED}

The principal selection criteria for practices to become involved with the Liverpool scheme were, and remain, enthusiasm and commitment to learning/teaching and suitable facilities. In addition, of course, it is necessary to understand the nature of the Liverpool curriculum. Consequently, a series of seminars was run in the spring and summer of 2000 to prepare practices in the Furness area to begin taking students from September 2000. Furness was chosen as it had fewer practices already committed to Manchester students for the 2000-2001 academic year, a high level of enthusiasm at primary and secondary care level, good support facilities and modern and attractive accommodation at Furness General Hospital. In September 2000, the first Year 5 students were welcomed to the Furness area for their seven-week attachment, and a total of 35 students were placed over that academic year. Ewen Fraser, a GP at Ulverston Health Centre, was appointed as Community Clinical Teacher for the Furness area and continues to oversee developments there. In the current academic year (2001-2002) a further 40 students in five blocks of eight are coming to the Furness area for their Year 5 community placements.

Year 5 community placements in Lancaster and South Lakes began in the current academic year following a series of seminars run in summer 2001. Karen Oliver, a GP based in Kendal, has been appointed as Community Clinical Teacher for this part of the scheme. Over the academic year there are five tranches of eight students doing their seven-week community attachments. Karen has been experimenting in terms of hospital base for tutorials and site for accommodation between Lancaster and Kendal. The geographical area is enormous and the steering committee is mindful of the distances to be travelled by some students to reach their allocated practices. At present, students are accommodated at Westmorland General Hospital and meet for their weekly 'half-day release course' either at WGH or a GP practice in Kendal.

\section{TIPS COURSES}

TIPS stands for Teacher Improvement Programme. A key objective of the steering committee has been to invest in the training of members of the primary care teams involved in the Liverpool scheme. To this end, two residential TIPS course have already been run in 2001 and more are planned. TIPS is led by Nigel Purcell, Staff Development Officer at Liverpool University Medical School and is designed as a foundation course in educational principles and methods. The course consists of a mix of video-taped 'practice-teaching' sessions plus talks and activities. Areas covered include:

- understanding and applying the basic principles of effective education

- formulating effective learning objectives

- developing strategies for structured learning in the healthcare setting

- planning and delivering presentations

- using questions to promote active learning and thinking

- evaluating the effectiveness of a teaching session

- assessing student learning

- giving effective and constructive feedback

A total of 30 Morecambe Bay GPs have now been through the course, in addition to three practice managers and two practice nurses. The feedback from participants has been excellent and hence it is planned to run further basic TIPS courses and more advanced courses, resources permitting, in the coming months and years.

\section{THE YEAR 5 COMMUNITY PLACEMENT}

A total of 80 students per year will continue to come to Morecambe Bay for their Year 5 community-orientated medical practice module until at least the academic year 2004/5. Forty will be based at Furness and 40 based at Lancaster/Kendal. In 2004, the number may drop to 50 students per year, but this will be offset by the arrival of 50 Year 4 students.

The Year 5 community module requires students to spend a minimum of two days per week directly involved in GP practice-related activities. At least one half-day is to be spent with the student acting, as far as possible and under supervision, as a GP. This includes seeing patients, handling phone calls, checking results and letters, writing (but not signing) prescriptions and being involved with the multifaceted events of a GP's day. Other activities include working with members of the primary care teams and performing a SWOT (Strengths, Weaknesses, Opportunities, Threats) analysis of some aspect of the practice's activity. Feedback from practices indicates that well-directed SWOT analyses undertaken by medical students can provide valuable management information to the primary care teams.

During the remainder of the week, students attend a halfday release course in either Barrow or Kendal, write up their portfolios and are encouraged to seek other self-directed learning opportunities either in the hospital or community settings. In the future, we expect to develop further structured communication skills and clinical skills training sessions to supplement the curriculum.

\section{YEAR 4 COMMUNITY PLACEMENTS}

A pilot tranche of 24 students are coming to Morecambe Bay in September 2003 to spend their full academic year here. From September 2004, there will be 50 Year 4 students per 
year spending their full academic year in Morecambe Bay. In Year 4, pairs of students spend one day a week, for 36 weeks, attached to general practices. Consequently we will need to recruit 12 practices for $2003 / 4$ and 25 practices for 2004/5 to handle this development. The GP attachments in Year 4 place emphasis on developing a broad understanding of primary and community care and the primary care team as a whole. Students require supervised access to patients and their medical records, a full range of primary care clinics, and all members of the primary care team. As we move towards 2003 the steering committee will look to identify practices interested in taking Year 4 students.

\section{SPECIAL STUDY MODULES (SSMS)}

Interspersed throughout the Liverpool medical course are Special Study Modules. These are compulsory four-week periods of specialised supervised study. They are designed to encourage diversity of approach and to give students the choice and opportunities to explore particular interests, while developing intellectual and practical skills. SSMs can be clinically or laboratory based and/or involve reviews of literature or of data.

SSMs can be run in primary care, secondary care, academic institutions and health service management. They present a real opportunity for anyone involved with health who has a particular interest or skill to convene a module and share their enthusiasm. The next applications to provide SSMs will need to be submitted by February 2003 in order to start in September 2003, so information events are planned for later this year, to facilitate development. In the meantime, anyone interested in developing an SSM should contact Peter Benning at the Education Centre at Royal Lancaster Infirmary for more information.

\section{FUTURE DEVELOPMENTS}

Developing and sustaining the level of educational involvement described requires ongoing and substantial investment in people, equipment and buildings. Already, over 30 practices across Morecambe Bay have been directly involved in supervising Liverpool University medical students and this number is set to rise. GPs and members of the primary care teams have already undertaken a good deal of new training and this must continue. Two Community Clinical Tutor posts have been established and other appointments are anticipated in the future. In addition, new capital for primary care developments is anticipated as we move towards 2004.

The Liverpool curriculum has a strong primary care orientation. Its ambition is to produce caring and competent clinicians who are lifelong learners and who understand the role and place of medicine in contemporary society. In Morecambe Bay we have the opportunity and privilege to embrace this ambition and to add our own special ingredient to the cocktail. In doing so we can develop our own clinical practice, enhance the environment in which we work, improve the care of our patients and support the future of our local health system. Please get in touch with us if you share these visions and would like further involvement with the community-orientated parts of the Liverpool University Medical School scheme in Morecambe Bay.

Primary care contacts for more information:

Jim Gardner, Primary Care Co-ordinator, MBPCT

jim.gardner@gp-A82025.nhs.uk

Ewen Fraser, Community Clinical Teacher, Furness

ewenandjenny@freenetname.co.uk

Karen Oliver, Community Clinical Teacher, Lancaster \& South Lakes karenoliver@doctors.org.uk

\section{LANCASTER MEDICAL BOOK CLUB PRIZE}

The Lancaster Medical Book Club Prize is awarded annually to the author(s) of the best paper in any medical discipline submitted by book club member(s) to the adjudicators. The prize was established in 1975, the following acting as trustees: Dr John Findlater, the president of the Book Club and the treasurer of the Book Club.

\section{The prize}

Currently the prize is $£ 250$ annually, but the adjudicators have the discretion to withhold, apportion or award accumulated income as necessary. The winning paper is announced at the annual dinner.

\section{Eligibility}

All members of the Lancaster Medical Book Club are entitled, either individually or in collaboration, to submit papers. In addition, since 1993 all junior doctors working in the Lancaster district, and all trainee general practitioners registered with the Lancaster scheme, have been offered temporary membership of the book club to enable them to submit papers.

\section{Submissions}

Candidates may submit a paper in any medical discipline containing original content in which they have actively participated. Such papers should be submitted to the Secretary of the Lancaster Medical Book Club, at the Postgraduate Medical Centre, RLI, prior to 1st September annually. The Book Club will not hold any right to any paper submitted.

\section{Adjudication}

The adjudicators are: the president, the president-elect, the secretary, the secretary-elect and the archivist who have the discretionary power to seek outside opinions regarding the merit of any submissions. Members of the Faculty of Medicine of Manchester University are suggested as an appropriate body for such consultation. Adjudicators will not assess any of their own submissions.

If you have a paper to submit please ensure it reaches the book club secretary before the closing date. 